\title{
Correction to: Use of response surface methodology for optimizing the media of establishment and proliferation phases of Iranian seedless barberry
}

\author{
Rahim Nazary Moghaddam Aghayeh ${ }^{1} \cdot$ Bahram Abedy $^{1} \cdot$ Ahmad Balandari $^{2} \cdot$ Leila Samiei $^{3} \cdot$ Ali Tehranifar $^{1}$
}

Published online: 11 February 2020

(c) Springer Nature B.V. 2020

Correction to: Plant Cell, Tissue and Organ Culture (PCTOC)
https://doi.org/10.1007/s11240-020-01769-7

There was a mix-up of figures, figure captions and citations throughout the initial online publication. The original article has been corrected.

Publisher's Note Springer Nature remains neutral with regard to jurisdictional claims in published maps and institutional affiliations.

The original article can be found online at https://doi.org/10.1007/ s11240-020-01769-7.

Bahram Abedy

Abedy@um.ac.ir

1 Department of Horticultural Science and Landscape, Faculty of Agriculture, Ferdowsi University of Mashhad, Mashhad, Iran

2 Khorasan Science and Technology Park (KSTP), Mashhad, Iran

3 Department of Ornamental Plants, Research Center for Plant Sciences, Ferdowsi University of Mashhad, Mashhad, Iran 